\title{
Karyotype analysis from four species of edible plants in northeastern Thailand
}

\author{
SURAPON SAENSOUK ${ }^{1}$, NATKAMON SAEN-IN ${ }^{1}$, PIYAPORN SAENSOUK ${ }^{2, \bullet}$ \\ ${ }^{1}$ Walai Rukhavej Botanical Research Institute, Mahasarakham University. Kantharawichai, Maha Sarakham 44150, Thailand \\ ${ }^{2}$ Plant and Invertebrate Taxonomy and Its Applications Unit Group, Department of Biology, Faculty of Science, Mahasarakham University. \\ Kantharawichai, Maha Sarakham 44150, Thailand. Tel. +66 4375 4247, ”email: pcornukaempferia@yahoo.com
}

Manuscript received: 12 September 2021. Revision accepted: 12 November 2021.

\begin{abstract}
Saensouk S, Saen-in N, Saensouk P. 2021. Karyotype analysis from four species of edible plants in northeastern Thailand. Biodiversitas 22: 5317-5324. Karyotype analysis from four species of edible plants, namely one species from family Cannaceae (Canna indica L.), one species including 2 variants from family Araceae (Colocasia esculenta (L.) Schott, green taro and black taro) and two species from family Apiaceae (Eryngium foetidum L. and Centella asiatica (L.) Urb.) in Maha Sarakham province, northeastern Thailand were determined from root tips. The results showed that the chromosome numbers and karyotype formulae were $2 n=28=$ $14 \mathrm{~m}+10 \mathrm{sm}+4 \mathrm{st}$ ( 2 sat) with $\mathrm{NF}=56$ for green taro, $2 n=42=20 \mathrm{~m}+20 \mathrm{sm}+2 \mathrm{st}$ (3sat) with $\mathrm{NF}=84$ for black taro, $2 n=18=18 \mathrm{sm}$ with $\mathrm{NF}=36$ for Centella asiatica $(\mathrm{L}$.) Urb., $2 \mathrm{n}=16=2 \mathrm{~m}+14 \mathrm{sm}$ with $\mathrm{NF}=32$ for Eryngium foetidum $\mathrm{L}$., $2 n=27=2 \mathrm{~m}+25 \mathrm{sm}$ with $\mathrm{NF}=54$ for Canna indica L. Both taros had differences in the chromosome numbers and karyotype formulae. The chromosomes of both taros were the asymmetrical karyotype. While, the chromosome structure of both taros, including the number of metacentric, submetacentric and subtelocentric as well as the position of satellite-chromosomes, were found to be different, which indicated inter-and intra-specific variations in this species. Therefore, the chromosome number, karyotype formula, chromosome structure, position of satellitechromosomes and idiogram can be used for classification of both taros in this study. Moreover, idiograms of both taros were reported for the first time. The karyotype, NF, RL, CI and ideogram of Centella asiatica (L.) Urb., Eryngium foetidum L. and Canna indica L. were reported for the first time.
\end{abstract}

Keywords: Edible plants, chromosome number, karyotype, idiogram

\section{INTRODUCTION}

Edible plants are very important to human life and wellbeing because it is an important source of food. In addition, edible plants are diverse and have great nutritional benefits. It is also a plant that can be cultivated and readily available locally. In addition, edible plants are also a source of local knowledge and wisdom, which have been passed down through generations, such as cooking or vegetables, which all point to the relationship between lifestyle and diversity of local vegetables in the community as well. Commonly cultivated edible plants are garlic, galingale, corn, ginger, galangal, rice, sesame, gourd, cucumber, coriander, morning glory, taro, chili, pepper, pumpkin, zucchini, shallot, etc (Boyce et al. 2012, Pholhiamhan et al. 2018). Taro is a very popular tuber crop of economic significance (Gogoi and Borah 2013). The edible plants are also found in Maha Sarakham Province, Northeast Thailand is an area where many food crops are grown. There are also some edible plants that are popularly cultivated as vegetables or used as raw materials for high-yielding dishes as a means of earning a living. These edible plants are taro, Asiatic leaf, dill, Indian sago.

During the study of aquatic plants in Maha Sarakham Province, the researchers found that these aquatic plants to be edible plants were taro (Colocasia esculenta (L.) Schott.), Asiatic leaf (Centella asiastica (L.) Urb.), dill (Eryngium foetidum L.), Indian sago (Canna indica L.). It was also found that taro has 2 variations, namely black taro and green taro. Both taros have been found to have similar morphological characters, but there are many variations in their morphology. We identified those specimens from the available literature, which showed that both taros have been found to be the same species, C. esculenta (L.) Schott. Therefore, the chromosome structure, variations in chromosome number and karyotypes might be different. The information of this research will support future cytological studies to be more comprehensive. The aim of this study was to study the chromosome numbers, karyotype and idiogram analysis of four species (include two variants) in edible plants, namely black taro, green taro, Asiatic leaf, dill, Indian sago from Maha Sarakham Province, Northeast Thailand. Taro is a very popular tuber crop of economic significance (Gogoi and Borah 2013). The chromosome numbers and karyotypes of taro $(C$. esculenta (L.) Schott) were previously studied by several workers (Ramachandran 1978; Kuruvilla and Singh 1981; Zhang and Yang 1984; Coates et al. 1988; Subramanian and Munian 1988; Huang et al. 1989; Kuruvilla et al. 1989; Li 1989; Sreekumari and Mathew 1989; Zhang 1998; Ivancic and Lebot 1999; Senavongse et al. 2018) (Table 2).

The chromosome numbers of Asiatic leaf (Centella asiastica (L.) Urb.) $2 n=18$ and 36 were previously studied by Kokubugata et al. (1998), while karyotypes of Asiatic leaf is never studied before (Table 2). Next, the chromosome numbers $2 n=16$ of dill (Eryngium foetidum 
L.) were previously studied by Hore (1980) and Guerra (1986). For the karyotypes of dill is never studied before (Table 2). For the chromosome numbers $2 n=18,27,36$ of Indian sago (Canna indica L.) were previously studied by Belling (1925) and Hanson et al. (2001), while karyotypes of Asiatic leaf is never studied before (Table 2).

\section{MATERIALS AND METHODS}

Four species of edible plants, namely taro (Colocasia esculenta (L.) Schott.) including two variants i.e. green taro and black taro, Asiatic leaf (Centella asiastica (L.) Urb.), dill (Eryngium foetidum L.), Indian sago (Canna indica L.) were collected in fields from Maha Sarakham Province, northeastern, Thailand (Figure 1). The comparative morphology of two variants of taro was provided (Figure 1, Table 1). All four species were grown in a nursery at the Walai Rukhavej Botanical Research Institute,
Mahasarakham University, Maha Sarakham Province, Thailand. The chromosome numbers study from root tips followed the methods of Saensouk et al. (2019) and Senavongse et al. $(2018 ; 2020)$. Photographs were taken using a light microscope (Zeiss: Axiostar plus) at $100 \times$ magnification.

The classification of the karyotype symmetry degree is proposed following Stebbins (1971). The diploid chromosome numbers of each specimen in this study were counted from 20 cells. For the arrangement of the karyotypes, the following parameters, such as average length of the short arm (Ls), average length of the long arm (Ll), length of each chromosome (LT), average measurement of relative length (RL), chromosome index (CI), standard deviation (SD) of RL and CI from metaphase chromosomes, were calculated by the methods of Saensouk et al. (2019), Senavongse et al. (2018; 2020), Saensouk and Saensouk (2021a) and Saensouk and Saensouk (2021b).

Table 1. Comparative analysis of morphological characteristics of both taros (Colocasia esculenta (L.) Schott) in this study

\begin{tabular}{lllllc}
\hline \multirow{2}{*}{ Specimens } & \multicolumn{5}{c}{ Characteristics } \\
\cline { 2 - 6 } & Petiole & Leaf color & Inside corm color & Local Thai name & Common name \\
\hline Green Taro & Light green & Light green & Light cream-purple & Peuak-Kan-Khiao & Green taro \\
Black Taro & Dark purple & Dark green & Dark cream-purple & Peuak-Kan-Dam & Black taro \\
\hline
\end{tabular}


Figure 1. Morphology of edible plants four species with two variants of taro from Maha Sarakham Province, northeastern, Thailand. A.Green taro (A1: shoot, A2: corm with inside corm), B.Black taro (B1: shoot, B2: corm with inside corm), C. Asiatic leaf (Centella asiatica (L.) Urb.), D. dill (Eryngium foetidum L.), E. Indian sago (Canna indica L.) 


\section{RESULTS AND DISCUSSION}

The comparative morphology characteristics of the green taro and black taro in this study are described, follow the green taro has light green color in petiole and leaf and light cream-purple color in inside corm but black taro has dark purple color in petiole, dark green color in leaf and dark cream-purple color in inside corm (Figures 1A, 1B and Table 1). The dominant characteristics of Asiatic leaf (Centella asiastica (L.) Urb.) has leaves borne on pericladial petioles (Figure 1C) For dill (Eryngium foetidum L.) has leaf blade flat with margins serrate (Figure 1D) and Indian sago (Canna indica L.) has leaves like banana leaves, rhizome arrow root (Figure 1E).

Chromosome numbers, karyology (fundamental number (NF), karyotype formula and satellite) and location in this study and those studied previously of taro (Colocasia esculenta (L.) Schott.) include two variants i.e. green taro and black taro, Asiatic leaf (Centella asiastica (L.) Urb.), dill (Eryngium foetidum L.), Indian sago (Canna indica L.) were presented in Table 2. The karyotypes and idiograms varied in composition for each chromosome shape amongbothspecimens (Figures 3, 4). The karyotype formulas of the taros are as follows:

Green Taro (Colocasia esculenta (L.) Schott.) $=2 n=$ $28=14 \mathrm{~m}+10 \mathrm{sm}+4 \mathrm{st}$ (2 sat)

Black Taro (C. esculenta (L.) Schott.) $=2 n=42=$ $20 \mathrm{~m}+20 \mathrm{sm}+2 \mathrm{st}$ (3 sat) $18 \mathrm{sm}$

Asiatic leaf (Centella asiatica (L.) Urb.) $=2 n=18=$

Dill (Eryngium foetidum L.) $=2 n=16=2 \mathrm{~m}+14 \mathrm{sm}$

Indian sago (Canna indica $\mathrm{L}$. $)=2 n=27=2 \mathrm{~m}+25 \mathrm{sm}$

\section{Colocasia esculenta (L.) Schott. (green taro and black taro)}

The results indicated that the somatic chromosome number of green taro was $2 n=28$ (Figure 2A). This was the same as several other workers who studied the chromosome numbers of $C$. esculenta (L.) Schott, as present in Table 2, such as Ramachandran (1978); Kuruvilla and Singh (1981); Zhang and Yang (1984); Tanimoto and Matsumoto (1986); Coates et al. (1988); Subramanian and Munian (1988); Huang et al. (1989); Kuruvilla et al. (1989); Li (1989); Sreekumari and Mathew (1989); Zhang (1998); Ivancic and Lebot (1999), Senavongse et al. (2018), The NF was found to be 56. The karyotype formula was found to be asymmetrical, including 14 metacentric $(\mathrm{m})$ pairs, 10 submetacentric $(\mathrm{sm})$ pairs and four subtelocentric (st) and two visible satellites, and its formula was $14 \mathrm{~m}+10 \mathrm{sm}+4 \mathrm{st}$ (2sat) (Figures $3 \mathrm{~A}, 4 \mathrm{~A}$ and Table 2), which was inconsistent with a previous study by Sreekumari and Mathew (1991a) who was reported the karyotype formulae $20 \mathrm{~m}+8 \mathrm{sm}, \quad 20 \mathrm{~m}+6 \mathrm{sm}+2 \mathrm{a}$, $18 \mathrm{~m}+8 \mathrm{sm}+2 \mathrm{a}, 22 \mathrm{~m}+2 \mathrm{sm}+6 \mathrm{a}$ and $6 \mathrm{~m}+12 \mathrm{sm}+10 \mathrm{a}$ (Table 2). In addition, Senavongse et al. (2018) reported differences from this study for the karyotype formula with five satellites (Table 2), due to the effects of environmental factors. The short arm length ranged from $1.03 \pm 0.11$ to $2.29 \pm 0.26 \mu \mathrm{m}$, the long arm length ranged from $1.58 \pm 0.10$ to $4.68 \pm 0.54 \mu \mathrm{m}$ and the total chromosome length ranged from $2.61 \pm 0.19$ to $6.97 \pm 0.54 \mu \mathrm{m}$. The relative length of the karyotype is a value between 3.87 to $10.49 \%$ (Table 2). The centromeric indexes were 0.50-0.72 (Table 2; Figures $2 \mathrm{~A}, 3 \mathrm{~A}, 4 \mathrm{~A})$. The created ideogram was based on the lengths of the chromosome arms and presented the point of the centromere (Figure 4A).

Black taro presented the somatic chromosome number tobe 42 (Figure 2B), which was consistent with the reports of Subramanian and Munian (1988) and Zhang (1998), while it differed from that of Huang et al. (1989) of $2 n=36$ (Table 2). The NF was found to be 84 . The karyotype formula of this specimen was found to be an asymmetrical, karyotype $20 \mathrm{~m}+20 \mathrm{sm}+2 \mathrm{st}$ (3sat), including 20 metacentric (m) pairs, 20 submetacentric $(\mathrm{sm})$ pairs and two subtelocentric (st) and three visible satellites (Figures 3B, $4 \mathrm{~B}$ and Table 2). The present results differ from previous reportsdue to the effects of environmental factors, i.e. Parvin et al. (2008) who reported $38 \mathrm{~m}+4 \mathrm{sm}$ without chromosome satellites and Senavongse et al. (2018) reported a karyotype formula with five satellites (Table 2). The short arm length ranged from $1.16 \pm 0.07$ to $2.28 \pm 0.10$ $\mu \mathrm{m}$, the long arm length ranged from $2.10 \pm 0.11$ to $4.01 \pm 0.30 \mu \mathrm{m}$ and the total chromosome length ranged from $3.33 \pm 0.11$ to $6.07 \pm 0.35 \mu \mathrm{m}$. The relative length of the karyotype is a value between 3.92 to $7.15 \%$ (Table 4). The centromeric indexes were $0.50-0.68$ (Table 4, Figures 2B, $3 \mathrm{~B}, 4 \mathrm{~B})$. The created ideogram was based on the lengths of the chromosome arms and presented the point ofthecentromere (Figure 4B).

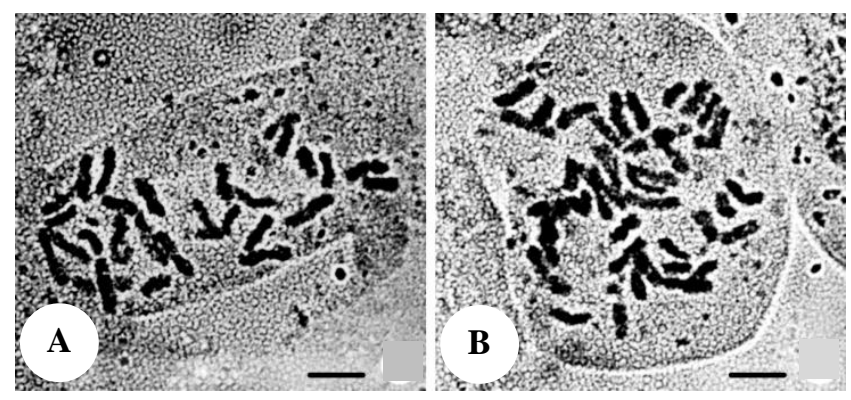

Figure 2. Somatic metaphase chromosomes of taros $(C$. esculenta (L.) Schott). A. Green taro showing $2 n=28$, B. black taro showing $2 n=42$, scale bars $=5 \mu \mathrm{m}$

\section{A If Bs || || ||



Figure 3. Karyotypes of taros (C. esculenta (L.) Schott). A. Green taro $(2 n=28=14 \mathrm{~m}+10 \mathrm{sm}+4 \mathrm{st}$ (2sat), B. Black taro $(2 n=42=20 \mathrm{~m}+20 \mathrm{sm}+2 \mathrm{st}$ (3sat) $)$. Arrows indicate satellites, scale bars $=5 \mu \mathrm{m}$ 
Table 2. Chromosome numbers and karyological study of Colocasia esculenta (L.) Schott, Centella asiatica (L.) Urb., Eryngium foetidum L. and Canna indica L. were investigated in this study and those studied previously

\begin{tabular}{|c|c|c|c|c|c|c|c|}
\hline Family & Species & $\begin{array}{l}\text { Chromosome } \\
\text { numbers (2n) }\end{array}$ & NF & $\begin{array}{c}\text { Karyotype } \\
\text { formula }\end{array}$ & Satellite & Location & Previous studied \\
\hline \multirow{28}{*}{ Araceae } & Colocasia & 28,42 & - & - & - & India & Ramachandran (1978) \\
\hline & esculenta (L.) & 28,42 & - & - & - & India & Kuruvilla and Singh (1981) \\
\hline & Schott & 28,42 & - & - & - & China & Zhang and Yang (1984) \\
\hline & & 28,42 & - & - & - & Japan & Tanimoto and Matsumoto (1986) \\
\hline & & 28,42 & 56,84 & - & - & Australia & Coates et al. (1988) \\
\hline & & 42 & 84 & - & - & India & Subramanian and Munian (1988) \\
\hline & & 36 & - & - & - & China & Huang et al. (1989) \\
\hline & & 28 & - & - & - & China & Li (1989) \\
\hline & & 28 & - & - & - & India & Sreekumari and Mathew (1989) \\
\hline & & 28 & - & - & - & India & Kuruvilla et al. (1989) \\
\hline & & 28 & 56 & $20 m+8 s m$ & - & India & Sreekumari and Mathew (1991a) \\
\hline & & 28 (II) & 56 & $20 m+6 s m+2 a$ & - & India & Sreekumari and Mathew (1991a) \\
\hline & & 28 (III) & 56 & $18 m+8 s m+2 a$ & - & India & Sreekumari and Mathew (1991a) \\
\hline & & 28 (IV) & 56 & $22 m+2 s m+6 a$ & - & India & Sreekumari and Mathew (1991a) \\
\hline & & $28(\mathrm{~V})$ & 56 & $6 m+12 s m+10 a$ & - & India & Sreekumari and Mathew (1991a) \\
\hline & & 28 & - & - & - & India & Sreekumari and Mathew (1991b) \\
\hline & & 42,84 & - & - & - & India & Sreekumari and Mathew (1991) \\
\hline & & 28,42 & - & - & - & India & Sreekumari and Mathew (1995) \\
\hline & & 42 & - & - & - & China & Zhang (1998) \\
\hline & & 28 & - & - & - & New Caledonia & Ivancic and Lebot (1999) \\
\hline & & 42 & 84 & $38 m+4 s m$ & 一 & Bangladesh & Parvin et al. (2008) \\
\hline & & 28 & 56 & $24 m+4 s m$ & - & Thailand & Senavongse et al. (2018) \\
\hline & & 28 & 56 & $20 m+8 s m$ & $\begin{array}{l}\text { 8(SCR), } \\
\text { 2(STR) }\end{array}$ & Thailand & Senavongse et al. (2018) \\
\hline & & 28 & 56 & $22 m+6 s m$ & 10(SCR) & Thailand & Senavongse et al. (2018) \\
\hline & & 28 & 56 & $24 m+4 s m$ & - & Thailand & Senavongse et al. (2018) \\
\hline & & 28 & 56 & $14 m+14 s m$ & - & Thailand & Senavongse et al. (2018) \\
\hline & & 28 & 56 & $14 m+10 s m+4 s t$ & $2(\mathrm{SCR})$ & Thailand & Present study (Green taro) \\
\hline & & 42 & 84 & $20 m+20 s m+2 s t$ & $3(\mathrm{SCR})$ & Thailand & Present study (Black taro) \\
\hline \multirow[t]{5}{*}{ Apiaceae } & $\begin{array}{l}\text { Centella } \\
\text { asiatica }(\mathrm{L} .)\end{array}$ & 18,36 & & - & - & $\begin{array}{l}\text { Australia } \\
\text { and Japan }\end{array}$ & Kokubugata et al. (1998) \\
\hline & Urb. & 18 & $36^{*}$ & $18 \mathrm{sm} *$ & - & Thailand & Present study \\
\hline & Eryngium & 16 & - & - & - & Brazil & Guerra (1986) \\
\hline & foetidum $\mathrm{L}$. & 16 & - & - & - & India & Hore (1980) \\
\hline & & 16 & $32 *$ & $2 m+14 s m^{*}$ & - & Thailand & Present study \\
\hline \multirow[t]{2}{*}{ Cannaceae } & Canna indica $\mathrm{L}$. & 18,27 & - & - & - & Japan & Belling (1925) \\
\hline & & 27 & $54 *$ & $2 m+25 s m *$ & - & Thailand & Present study \\
\hline
\end{tabular}

Note: *the first time report, M: metacentric chromosome, sm: submetacentric chromosome, a: acrocentric chromosome, st: subtelocentric chromosome, STR: subtelomeric region, SCR: subcentromeric regions, $\rightarrow$ not available

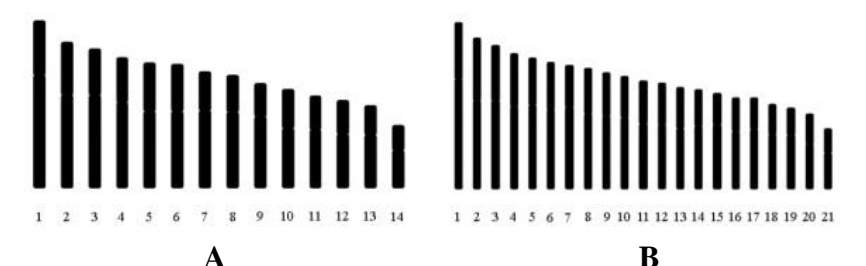

Figure 4. Idiograms of taros (C. esculenta (L.) Schott). A.Green taro, B.Black taro

However, the chromosome number of taro (C. esculenta (L.) Schott) agrees with the majority of previous reports (Table 2), while Sharma and Sarkar (1963) reported $2 n=$ 22, 26, 38 and Huang et al. (1989) reported $2 n=36$, which are consistent with Senavongse et al. (2018) who reported various chromosome numbers for $C$. esculenta (L.) Schott. Comparative morphology between the taros found that the chromosome number of green taro might be diploid because it was found to be the dominant characteristic in light green petioles and leaves, including light cream inside corm, and the chromosome number of black taro might be triploid because it was found to be the dominant characteristic in dark petioles and leaves, including dark inside corm, which was consistent with the report of Coates et al. (1988). They reported the somatic chromosome numbers of $C$. esculenta (L.) Schott as 28 and 42, which characterized this species to be diploid and triploid, respectively. This study found karyotype asymmetry with satellite-chromosomes, while Senavongse et al. (2018) reported karyotype symmetry with satellite-chromosomes of C. esculenta (L.) Schott because of the effects of environmental factors. These cytological data can be used as evidence in the study of evolutionary relationships and 
can also help to identify the species (Senavongse et al. 2020) as an important taxonomic character (Wahidi and Nursyahra 2018). Idiograms of both taros are reported for the first time.

In this study, the chromosome numbers of the taro specimens, green taro and black taro $(C$. esculenta (L.) Schott) are different, green taro $(2 n=28)$ and black taro $(2 n=42)$ (Figure 2 and Table 2). The taros have asymmetrical karyotypes, which differ in chromosome structure, including number of metacentric, submetacentric and subtelocentric and the position of satellitechromosomes as the morphological characteristics of the taro specimens have similar morphologies, but mainly differ in their morphology (petiole color, leaf color, inside corm color), as shown in Figure 1 and Table 1. Therefore, the chromosome number, karyotype formula, chromosome structure, position of satellite-chromosomes and idiograms can be used for classification of both specimens of taro in this study.

\section{Centella asiatica (L.) Urb.}

The cytogenetic of Centella asiatica (L.) Urb. was found that the somatic chromosome number of $C$. asiatica (L.) Urb. was presented tobe 18 (Figure 5A), which was consistent with the reports of Kokubugata et al. (1998) (Table 2). The NF was found to be 36. The karyotype formula of this species was an asymmetrical, karyotype 18 sm, including 18 pairs submetacentric (sm)-type (Figures 5B, 5C and Table 2). The short arm length ranged from $0.53 \pm 0.03$ to $0.94 \pm 0.21 \mu \mathrm{m}$, the long arm length ranged from $0.89 \pm 0.09$ to $1.61 \pm 0.31 \mu \mathrm{m}$ and the total chromosome length ranged from $1.42 \pm 0.12$ to $2.55 \pm 0.43 \mu \mathrm{m}$. The relative length of the karyotype is a value between 8.18 to $14.62 \%$ (Table 5). The centromeric indexes were $0.54-0.73$ (Table 5 and Figures 5B, 5C). The created ideogram was based on the lengths of the chromosome arms and presented the point of the centromere (Figure 5C). The NF, the karyotype, RL, CI and ideogram of $C$. asiatica were reported for the first time (Tables 2, 5).

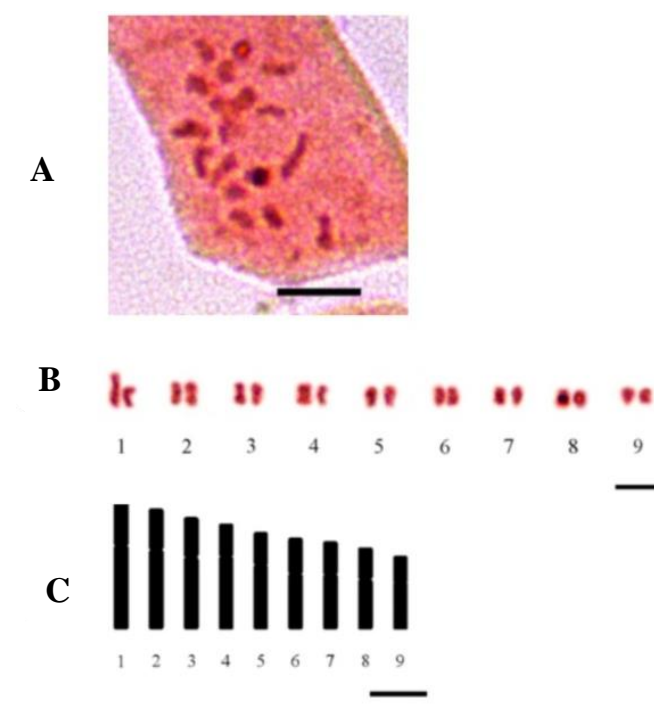

Figure 5. Chromosome of $C$. asiatica A. Somatic metaphase chromosome number showing $2 n=18$, B. Karyotype showing $18 \mathrm{sm}$, C. Idiogram, scale bars $=5 \mu \mathrm{m}$
A
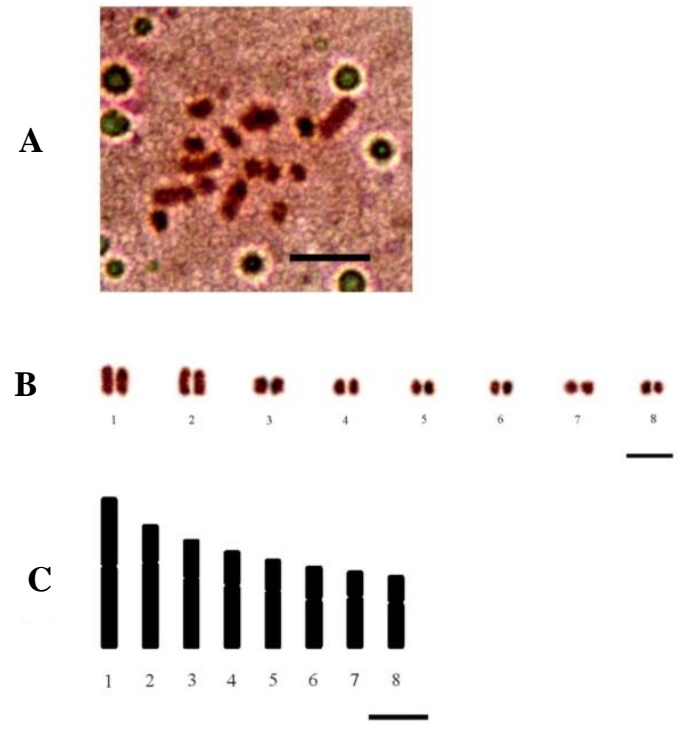

Figure 6. Chromosome of Eryngium foetidum L. A. Somatic metaphase chromosome number showing $2 n=16$, B. Karyotype showing $2 \mathrm{~m}+14 \mathrm{sm}$, C. Idiogram, scale bars $=5 \mu \mathrm{m}$

A
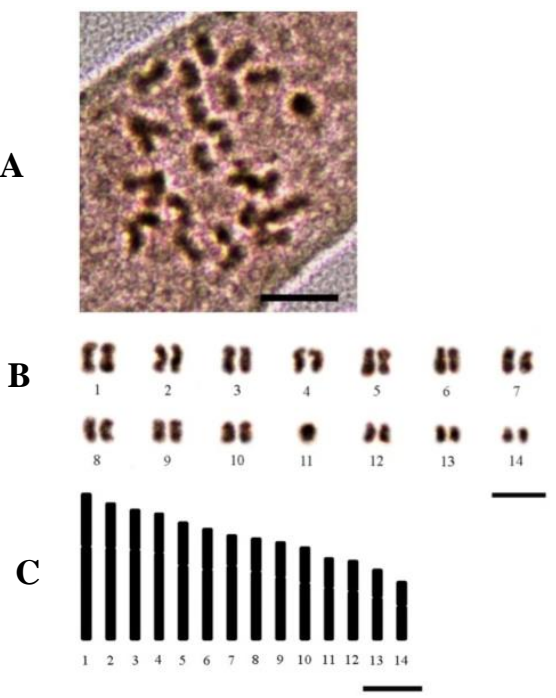

Figure 7. Chromosome of Canna indica L. A. Somatic metaphase chromosome number showing $2 n=27$, B. Karyotype showing $2 \mathrm{~m}$ $+25 \mathrm{sm}, \mathrm{C}$. Idiogram, scale bars $=5 \mu \mathrm{m}$

\section{Eryngium foetidum $\mathbf{L}$.}

The cytogenetic of Eryngium foetidum L. was found that the chromosome number of E. foetidum L. was presented the somatic chromosome number to be 16 (Figure 6A), which was consistent with the reports of Guerra (1986) and Hore (1980) (Table 2). The NF was found to be 32. The karyotype formula of this species was an asymmetrical, karyotype $2 \mathrm{~m}+14 \mathrm{sm}$, including two pair metacentric (m)-type and 14 pairs submetacentric (sm)type (Figures 6B, 6C and Table 2). The short arm length ranged from $0.58 \pm 0.11$ to $1.06 \pm 0.16 \mu \mathrm{m}$, the long arm length ranged from $1.01 \pm 0.14$ to $2.23 \pm 0.38 \mu \mathrm{m}$ and the total chromosome length ranged from $1.60 \pm 0.28$ to $3.29 \pm 0.32 \mu \mathrm{m}$. The relative length of the karyotype is a 
value between 10.73 to $22.51 \%$ (Table 6). The centromeric indexes were 0.59-0.69 (Table 6; Figures 6B, 6C). The created ideogram was based on the lengths of the chromosome arms and presented the point of the centromere (Figure 6C). The NF, the karyotype, RL, CI and ideogram of E. foetidum L. were reported for the first time (Tables 2, 6).

\section{Canna indica $\mathrm{L}$.}

The cytogenetic of Canna indica L. was found that the chromosome number of $C$. indica $\mathrm{L}$. was presented the somatic chromosome number tobe 27 (Figure 7A), which was consistent with the reports of Belling (1925) (Table 2). The NF was found to be 54. The karyotype formula of this species was an asymmetrical, karyotype $2 \mathrm{~m}+25 \mathrm{sm}$, including two pair metacentric (sm)-type and 25pairs (Figures 7B, 7C and Table 2). The short arm length ranged from $0.53 \pm 0.03$ to $0.94 \pm 0.21 \mu \mathrm{m}$, the long arm length ranged from $0.89 \pm 0.09$ to $1.61 \pm 0.31 \mu \mathrm{m}$ and the total chromosome length ranged from $1.42 \pm 0.12$ to $2.55 \pm 0.43$ $\mu \mathrm{m}$. The relative length of the karyotype is a value between 8.18 to $14.62 \%$ (Table 7). The centromeric indexes were 0.54-0.73 (Table 7; Figures 7B, 7C). The created ideogram was based on the lengths of the chromosome arms and presented the point of the centromere (Fiure 7C). The NF, the karyotype, RL, CI and ideogram of $C$. indica $\mathrm{L}$. were reported for the first time (Tables 2, 7).

Table 3. Mean length of short arm chromosome (Ls), long arm chromosome (Ll), total arm chromosome (LT), relative length (RL), centromeric index (CI), standard deviation (SD) of RL and CI from 20 metaphases of green taro (C. esculenta $(\mathrm{L}$.) Schott) $(2 n=28)$

\begin{tabular}{crrrrll}
\hline Chromosomepair & $\mathbf{L s}(\boldsymbol{\mu m}) \pm \mathbf{S D}$ & $\mathbf{L l}(\boldsymbol{\mu m}) \pm \mathbf{S D}$ & $\mathbf{L T}(\boldsymbol{\mu m}) \pm \mathbf{S D}$ & $\mathbf{R L}(\boldsymbol{\%})$ & CI & Chromosome type \\
\hline 1 & $2.29 \pm 0.26$ & $4.68 \pm 0.54$ & $6.97 \pm 0.54$ & 10.49 & 0.59 & Metracentric \\
2 & $2.23 \pm 0.21$ & $3.85 \pm 0.24$ & $6.08 \pm 0.27$ & 9.20 & 0.50 & Metracentric \\
3 & $1.94 \pm 0.20$ & $3.87 \pm 0.38$ & $5.81 \pm 0.51$ & 8.78 & 0.66 & Submetracentric \\
4 & $1.85 \pm 0.11$ & $3.56 \pm 0.07$ & $5.41 \pm 0.18$ & 8.19 & 0.51 & Metracentric \\
5 & $2.02 \pm 0.05$ & $3.19 \pm 0.21$ & $5.22 \pm 0.19$ & 7.90 & 0.62 & Submetracentric \\
$* 6$ & $1.98 \pm 0.25$ & $3.19 \pm 0.45$ & $5.18 \pm 0.69$ & 7.84 & 0.61 & Submetracentric \\
$* 7$ & $1.62 \pm 0.12$ & $3.23 \pm 0.09$ & $4.85 \pm 0.06$ & 7.36 & 0.58 & Metracentric \\
8 & $1.53 \pm 0.14$ & $3.16 \pm 0.11$ & $4.69 \pm 0.21$ & 7.08 & 0.61 & Submetracentric \\
9 & $1.41 \pm 0.37$ & $2.96 \pm 0.60$ & $4.37 \pm 0.96$ & 6.62 & 0.68 & Submetracentric \\
10 & $1.63 \pm 0.22$ & $2.47 \pm 0.19$ & $4.10 \pm 0.21$ & 6.21 & 0.59 & Metracentric \\
11 & $1.40 \pm 0.10$ & $2.43 \pm 0.15$ & $3.82 \pm 0.09$ & 5.77 & 0.55 & Metracentric \\
12 & $1.43 \pm 0.39$ & $2.23 \pm 0.54$ & $3.66 \pm 0.81$ & 5.52 & 0.53 & Metracentric \\
14 & $1.21 \pm 0.06$ & $2.22 \pm 0.18$ & $3.42 \pm 0.18$ & 5.18 & 0.72 & Subtelocentric \\
\hline
\end{tabular}

Note: *Satellite chromosome

Table 4. Mean length of short arm chromosome (Ls), long arm chromosome (Ll), total arm chromosome (LT), relative length (RL), centromeric index (CI), standard deviation (SD) of RL and CI from 20 metaphases of black taro (C. esculenta (L.) Schott) $(2 n=42)$

\begin{tabular}{crrrrll}
\hline Chromosome pair & Ls $(\boldsymbol{\mu m}) \pm$ SD & Ll $(\boldsymbol{\mu m}) \pm$ SD & LT $(\boldsymbol{\mu m}) \pm$ SD & RL $(\boldsymbol{\%})$ & CI & Chromosome type \\
\hline 1 & $2.06 \pm 0.16$ & $4.01 \pm 0.30$ & $6.07 \pm 0.35$ & 7.15 & 0.66 & Submetracentric \\
2 & $2.28 \pm 0.10$ & $3.23 \pm 0.09$ & $5.51 \pm 0.13$ & 6.49 & 0.57 & Metracentric \\
3 & $2.01 \pm 0.06$ & $3.22 \pm 0.05$ & $5.23 \pm 0.06$ & 6.17 & 0.58 & Metracentric \\
4 & $1.93 \pm 0.07$ & $3.01 \pm 0.14$ & $4.94 \pm 0.17$ & 5.84 & 0.68 & Submetracentric \\
5 & $1.71 \pm 0.17$ & $3.06 \pm 0.33$ & $4.77 \pm 0.40$ & 5.64 & 0.52 & Metracentric \\
6 & $1.72 \pm 0.19$ & $2.91 \pm 0.16$ & $4.63 \pm 0.09$ & 5.47 & 0.51 & Metracentric \\
7 & $1.53 \pm 0.08$ & $2.97 \pm 0.12$ & $4.50 \pm 0.07$ & 5.32 & 0.66 & Submetracentric \\
8 & $1.66 \pm 0.08$ & $2.75 \pm 0.09$ & $4.41 \pm 0.06$ & 5.21 & 0.62 & Submetracentric \\
9 & $1.58 \pm 0.29$ & $2.66 \pm 0.37$ & $4.24 \pm 0.64$ & 5.02 & 0.66 & Submetracentric \\
10 & $1.48 \pm 0.12$ & $2.61 \pm 0.12$ & $4.10 \pm 0.07$ & 4.84 & 0.60 & Submetracentric \\
11 & $1.61 \pm 0.05$ & $2.35 \pm 0.11$ & $3.95 \pm 0.07$ & 4.67 & 0.50 & Metracentric \\
12 & $1.55 \pm 0.08$ & $2.32 \pm 0.08$ & $3.87 \pm 0.09$ & 4.57 & 0.51 & Metracentric \\
13 & $1.50 \pm 0.34$ & $2.21 \pm 0.54$ & $3.71 \pm 0.87$ & 4.38 & 0.55 & Metracentric \\
$* 14$ & $1.32 \pm 0.25$ & $2.31 \pm 0.18$ & $3.62 \pm 0.13$ & 4.27 & 0.68 & Submetracentric \\
15 & $1.16 \pm 0.07$ & $2.34 \pm 0.09$ & $3.50 \pm 0.16$ & 4.12 & 0.67 & Submetracentric \\
16 & $1.22 \pm 0.06$ & $2.10 \pm 0.11$ & $3.33 \pm 0.11$ & 3.92 & 0.52 & Metracentric \\
17 & $1.15 \pm 0.16$ & $2.18 \pm 0.61$ & $3.33 \pm 0.75$ & 3.92 & 0.70 & Subtelocentric \\
18 & $1.11 \pm 0.24$ & $1.98 \pm 0.19$ & $3.09 \pm 0.23$ & 3.65 & 0.59 & Metracentric \\
19 & $1.00 \pm 0.14$ & $1.96 \pm 0.12$ & $2.96 \pm 0.06$ & 3.50 & 0.58 & Metracentric \\
20 & $1.11 \pm 0.07$ & $1.63 \pm 0.05$ & $2.74 \pm 0.05$ & 3.25 & 0.62 & Submetracentric \\
21 & $0.89 \pm 0.11$ & $1.31 \pm 0.23$ & $2.20 \pm 0.32$ & 2.59 & 0.63 & Submetracentric \\
\hline
\end{tabular}


Table 5. Mean length of short arm chromosome (Ls), long arm chromosome (Ll), total arm chromosome (LT), relative length (RL), centromeric index (CI), standard deviation (SD) of RL and CI from 20 metaphases of Centella asiatica (L.) Urb. $(2 n=18)$

\begin{tabular}{crrrrrl}
\hline Chromosomepair & $\mathbf{L s}(\boldsymbol{\mu m}) \pm \mathbf{S D}$ & $\mathbf{L l}(\boldsymbol{\mu m}) \pm \mathbf{S D}$ & $\mathbf{L T}(\boldsymbol{\mu m}) \pm$ SD & RL $(\boldsymbol{\%})$ & CI & Chromosome type \\
\hline 1 & $0.94 \pm 0.21$ & $1.61 \pm 0.31$ & $2.55 \pm 0.43$ & 14.62 & 0.63 & Submetracentric \\
2 & $0.79 \pm 0.17$ & $1.53 \pm 0.34$ & $2.32 \pm 0.48$ & 13.29 & 0.65 & Submetracentric \\
3 & $0.76 \pm 0.11$ & $1.40 \pm 0.16$ & $2.16 \pm 0.22$ & 12.40 & 0.64 & Submetracentric \\
4 & $0.63 \pm 0.08$ & $1.40 \pm 0.21$ & $2.03 \pm 0.27$ & 11.67 & 0.68 & Submetracentric \\
5 & $0.63 \pm 0.08$ & $1.24 \pm 0.13$ & $1.87 \pm 0.15$ & 10.77 & 0.66 & Submetracentric \\
6 & $0.70 \pm 0.16$ & $1.07 \pm 0.27$ & $1.76 \pm 0.41$ & 10.18 & 0.60 & Submetracentric \\
7 & $0.64 \pm 0.05$ & $1.06 \pm 0.19$ & $1.69 \pm 0.22$ & 9.78 & 0.62 & Submetracentric \\
8 & $0.61 \pm 0.17$ & $0.96 \pm 0.23$ & $1.57 \pm 0.39$ & 9.11 & 0.61 & Submetracentric \\
9 & $0.53 \pm 0.03$ & $0.89 \pm 0.09$ & $1.42 \pm 0.12$ & 8.18 & 0.63 & Submetracentric \\
\hline
\end{tabular}

Table 6. Mean length of short arm chromosome (Ls), long arm chromosome (Ll), total arm chromosome (LT), relative length (RL), centromeric index (CI), standard deviation (SD) of RL and CI from 20 metaphases of Eryngium foetidum L. $(2 n=16)$

\begin{tabular}{crrrrll}
\hline Chromosomepair & Ls $(\boldsymbol{\mu m}) \pm \mathbf{S D}$ & $\mathbf{L I}(\boldsymbol{\mu m}) \pm \mathbf{S D}$ & $\mathbf{L T}(\boldsymbol{\mu m}) \pm$ SD & RL $(\boldsymbol{\%})$ & CI & Chromosome type \\
\hline 1 & $1.06 \pm 0.16$ & $2.23 \pm 0.38$ & $3.29 \pm 0.32$ & 22.51 & 0.68 & Submetracentric \\
2 & $0.83 \pm 0.06$ & $1.88 \pm 0.39$ & $2.71 \pm 0.43$ & 18.24 & 0.69 & Submetracentric \\
3 & $0.83 \pm 0.13$ & $1.55 \pm 0.37$ & $2.38 \pm 0.44$ & 15.89 & 0.64 & Submetracentric \\
4 & $0.76 \pm 0.18$ & $1.39 \pm 0.32$ & $2.15 \pm 0.43$ & 14.27 & 0.65 & Submetracentric \\
5 & $0.70 \pm 0.14$ & $1.27 \pm 0.29$ & $1.96 \pm 0.35$ & 13.10 & 0.64 & Submetracentric \\
6 & $0.74 \pm 0.11$ & $1.07 \pm 0.29$ & $1.81 \pm 0.40$ & 12.13 & 0.59 & Metracentric \\
7 & $0.58 \pm 0.11$ & $1.13 \pm 0.31$ & $1.71 \pm 0.42$ & 11.36 & 0.66 & Submetracentric \\
8 & $0.60 \pm 0.17$ & $1.01 \pm 0.14$ & $1.60 \pm 0.28$ & 10.73 & 0.63 & Submetracentric \\
\hline
\end{tabular}

Table 7. Mean length of short arm chromosome (Ls), long arm chromosome (Ll), total arm chromosome (LT), relative length (RL), centromeric index (CI), standard deviation (SD) of RL and CI from 20 metaphases of Canna indica L. $(2 n=27)$

\begin{tabular}{crrrrrl}
\hline Chromosome pair & Ls $(\boldsymbol{\mu m}) \pm$ SD & $\mathbf{L l}(\boldsymbol{\mu m}) \pm \mathbf{S D}$ & $\mathbf{L T}(\boldsymbol{\mu m}) \pm$ SD & RL $(\boldsymbol{\%})$ & CI & Chromosome type \\
\hline 1 & $1.13 \pm 0.22$ & $1.97 \pm 0.18$ & $3.10 \pm 0.13$ & 10.02 & 0.63 & Submetracentric \\
2 & $0.95 \pm 0.16$ & $1.94 \pm 0.14$ & $2.90 \pm 0.13$ & 9.33 & 0.66 & Submetracentric \\
3 & $0.86 \pm 0.19$ & $1.91 \pm 0.83$ & $2.76 \pm 0.99$ & 8.90 & 0.69 & Submetracentric \\
4 & $0.85 \pm 0.08$ & $1.84 \pm 0.34$ & $2.68 \pm 0.34$ & 8.63 & 0.68 & Submetracentric \\
5 & $0.92 \pm 0.07$ & $1.57 \pm 0.22$ & $2.49 \pm 0.23$ & 8.01 & 0.63 & Submetracentric \\
6 & $0.87 \pm 0.28$ & $1.49 \pm 0.83$ & $2.36 \pm 1.08$ & 7.61 & 0.63 & Submetracentric \\
7 & $0.67 \pm 0.14$ & $1.56 \pm 0.17$ & $2.23 \pm 0.21$ & 7.21 & 0.69 & Submetracentric \\
8 & $0.72 \pm 0.13$ & $1.44 \pm 0.33$ & $2.16 \pm 0.41$ & 7.00 & 0.67 & Submetracentric \\
9 & $0.74 \pm 0.31$ & $1.33 \pm 0.43$ & $2.07 \pm 0.72$ & 6.72 & 0.64 & Submetracentric \\
10 & $0.76 \pm 0.08$ & $1.21 \pm 0.16$ & $1.97 \pm 0.14$ & 6.38 & 0.61 & Submetracentric \\
11 & $0.64 \pm 0.06$ & $1.10 \pm 0.06$ & $1.74 \pm 0.12$ & 5.68 & 0.63 & Submetracentric \\
12 & $0.65 \pm 0.22$ & $1.04 \pm 0.30$ & $1.69 \pm 0.48$ & 5.51 & 0.62 & Submetracentric \\
13 & $0.60 \pm 0.09$ & $0.90 \pm 0.04$ & $1.50 \pm 0.08$ & 4.91 & 0.60 & Submetracentric \\
14 & $0.53 \pm 0.10$ & $0.72 \pm 0.20$ & $1.25 \pm 0.20$ & 4.10 & 0.58 & Metracentric \\
\hline
\end{tabular}

In conclusion, this studies, the karyotype, NF, RL, CI and ideogramof chromosome study from edible aquatic plants from Maha Sarakham province, Thailand belongs to family Apiaceae (two species i.e. Centella asiatica (L.) Urb. and Eryngium foetidum L.) and family Cannaceae (one species, Canna indica L.) were reported for the first time. In addition, one more species of edible aquatic plants in this study, namely Colocasia esculenta (L.) Schott or taro (comprise of two variants, green taro and black taro) was studied comparative some morphologies and chromosome. The result found that the morphological characteristics of both taros specimens have similar morphologies, but mainly differ in their morphologies (petiole color, leaf color, inside corm color). The chromosome numbers and karyotype formula from root tips of both taros were $2 n=28=14 \mathrm{~m}+10 \mathrm{sm}+4 \mathrm{st}$ (2sat) with $\mathrm{NF}=56$ for green taro and $2 n=42=20 \mathrm{~m}+20 \mathrm{sm}+2 \mathrm{st}$ (3sat) with NF $=84$ for black taro. Therefore, karyotypes of both taros were taken asymmetrical but differ in NF, chromosome structure, including number of metacentric, submetacentric and subtelocentric and the position of satellite-chromosomes. Therefore, the morphology, the chromosome number, karyotype formula, chromosome structure, position of satellite-chromosomes and ideogram can be used for classification of both taros in this study. 
From available literatures were found that ideograms of both taros were never reported from previously study.

\section{ACKNOWLEDGEMENTS}

This research was financially supported by Walai Rukhavej Botanical Research Institute, Mahasarakham University through the Biodiversity and Conservation Research Unit, Walai Rukhavej Botanical Research Institute, Mahasarakham University, Thailand (FY2020). We appreciate support from the Walai Rukhavej Botanical Research Institute, Mahasarakham University, Maha Sarakham, Thailand for facilities during research. Many thanks to my family and friends for their support and help in the field. Many thanks to Dr. Jolyon Dodgson who is agriculturist, crop scientist, plant pathologist from UK for language editing and suggestions to improve the manuscript.

\section{REFERENCES}

Belling J. 1925. Chromosomes of Canna and of Hemerocallis. J Heredity 16 (12): 465-466.

Boyce PC, Sookchaloem D. 2012. Araceae. In: Santisuk, T. and Larsen, K. (eds.). Flora of Thailand. Prachachon Co., Ltd., Bangkok.

Coates DJ, Yen DE, Gaffey PM. 1988. Chromosome Variation in Taro, Colocasia esculenta: Implications for origin in the Pacific. Cytologia 53: 551-560.

Gogoi R, Borah S. 2013. Two new species and a new record for Colocasia (Araceae: Colocasieae) from Arunachal Pradesh. Northeast India. Gard Bull Sing 65: 27-37.

Guerra M. 1986. Citogenetica de Angiospermas coletadas en Pernambuco. Brazilian J Genet 9: 21-40.

Hore A. 1980. Structure and behaviour of chromosomes as an aid to the study of phylogeny of Umbelliferae with special reference to the tribe Apieae (Ammineae) and Saniculeae. Cytologia 45: 389-402.

Huang SF, Zhao ZF, Chen ZY, Chen SJ, Huang XX. 1989. Chromosome counts on one hundred species and infraspecific taxa. Acta Bot Austr Sin 5: 161-176.

Ivancic A, Lebot V. 1999. Botany and genetics of New Caledonian wild taro, Colocasia esculenta. Pacific Sci 53: 273-285.

Kokubugata G, Kondo K, Randall LM. 1998. Intraspecific polyploidy in Centella asiastica and their karyotypes in five populations in Australia and Japan. Chromosome Sci 2: 43-46.

Kuruvilla KM, Singh A. 1981. Karyotypic and electrophoretic studies on taro and its origin. Euphytica 30: 405-413.

Kuruvilla KM, Dutt B, Roy RP. 1989. Karyomorphological investigations on aroids of North-Eastern Hills. J Cytol Genet 24: 13-22.
Li RQ. 1989. Studies on Karyotypes of Vegetables in China. Wuhan University Press, Wuhan.

Parvin S, Kabir G, Ud-Deen MM, Sarker JK. 2008. Karyotype analysis of seven varieties of taro Colocasia esculenta (L.) Schott. from Bangladesh. J Biol Sci 16: 15-18. DOI: 10.3329/jbs.v16i0.3735.

Pholhiamhan R, Saensouk S, Saensouk P. 2018. Ethnobotany of Phu Thai ethnic group in Nakhon Phanom province, Thailand. Walailak J Sci Technol 15 (10): 679-699. DOI: 10.48048/wjst.2018.3737.

Ramachandran K. 1978. Cytological studies on South Indian Araceae. Cytologia 43: 289-303.

Saensouk S, Saensouk P, Senavongse R. 2019. Karyological study in three Thailand species of Colocasia (Araceae). Cytologia 84: 179-182. DOI: $10.1508 /$ cytologia.84.179.

Saensouk S, Saensouk P. 2021a. Karyotype analysis of three species of Allium (Amaryllidaceae) from Thailand. Biodiversitas 22 (8): 34583466. DOI: 10.13057/biodiv/d220844.

Saensouk P, Saensouk S. 2021b. Diversity and cytological studies on the genus Amomum Roxb. former Elettariopsis Baker (Zingiberaceae) in Thailand. Biodiversitas 22 (6): 3209-3218. DOI: 10.13057/biodiv/d220624.

Senavongse R, Saensouk S, Saensouk P. .2018Comparative karyotype analysis in five strains of Colocasia esculenta (L.) Schott (Araceae) in Thailand. Cytologia 83: 169-173. DOI: 10.1508/cytologia.83.169.

Senavongse R, Saensouk S, Saensouk, P. 2020. Karyological study of three native species of the genus Alocasia (Araceae) in the northeast of Thailand. Nucleus 63: 81-85. DOI: 10.1007/s13237-019-00278-z.

Sharma AK, Sarkar AK. 1963. Cytological analysis of different cytotypes of Colocasia antiquorum. Bull Bot Soc Bengal 17: 16-22.

Subramanian D, Munian M. 1988. Cytotaxonomical studies in South Indian Araceae. Cytologia 53: 59-66.

Sreekumari MT, Mathew PM. 1989. Karyomorphology of six cultivars of taro (Colocasia esculenta Schott). New Bot 16: 127-135.

Sreekumari MT, Mathew PM. 1991. Effect of colchicine treatment in a triploid variety of taro (Colocasia esculenta (L.) Schott). New Bot 18 : 211-215.

Sreekumari MT, Mathew PM. 1991a. Karyomorphology of five morphotypes of taro (Colocasia esculenta (L.) Schott). Cytologia 56: 215-218.

Sreekumari MT, Mathew PM. 1991b. Karyotypically distinct morphotypes in taro (Colocasia esculenta (L.) Schott). Cytologia 56: 399-402.

Sreekumari MT, Mathew PM. 1995. Karyotype distinction in Indian taros. J Cytol Genet 30: 143-149.

Stebbins GL. 1971. Chromosomal Evolution in Higher Plants. Edward Arnold, London.

Tanimoto T, Matsumoto T. 1986. Variations of morphological characters and isozyme patterns in Japanese cultivars of Colocasia esculenta Schott and C. gigantea Hook. Japanese J Breed 36: 100-111.

Wahidi I, Nursyahra. 2018. Starch and karyotype study of taro (Colocasia esculenta L.) from West Sumatra, Indonesia. Intl J Sci Res Pub 8: 256-260. DOI: 10.29322/IJSRP.8.10.2018.p8233.

Zhang CS. 1998. A preliminary study on making plant chromosomal specimens using peppermint oil compound as pretreatment agent. J Wuhan Bot Res 16: 280-282.

Zhang GM, Yang ZH. 1984. Studies on chromosome numbers of main cultivars of Colocasia esculenta in China. Acta Hort Sin 11: 187-190. 